\title{
Lambing and mortality rate in Ouled-Djellal sheeps in Tebessa region-Algeria
}

\author{
M. Douh ${ }^{1,2} *$, C. Aissaoui ${ }^{1}$, A. Hirech ${ }^{3}$ and S. Abdelmajid ${ }^{4}$ \\ ${ }^{1}$ Faculty of Science and Life Chadli Bendjedid University, El Taref, 36000, ${ }^{2}$ Biotechnology Research Center (CRBt), Ali \\ Mendjli Constantine 25000, ${ }^{3}$ Faculty of Science and Life Mohamed Kheider University, Biskra 07000, ${ }^{4}$ Institute of Agronomic \\ and Veterinary Sciences (INSAV), Mohamed Cherif Messaadia University Souk Ahrass 41000, Algeria. \\ * Corresponding author: mouraddouh@gmail.com
}

(Received March 7, 2018; Accepted May 16, 2018)

\begin{abstract}
The aim of this work is to study lamb births and mortalities in Algerian sheep Ouled Djellal breed distributed in different zones of Tébessa region, which is divided according to bioclimatic stage, staff in livestock and area agricultural vocation, into four distinct zones: northern (A, B), middle (C) and southern zone (D). During two years 2015-2016, birth numbers (BN) and mortality rates (MR) of 355 sheep flocks were recorded using a questionnaire. Concerning BN the total number was 21244 lambs representing a mean $59 \pm 31$ per flock. No significant differences between the birth means of $\mathrm{C}$ and $\mathrm{D}(75 \pm 28$ vs $83 \pm 30$ ) were registered. Birth mean was significantly higher $(\mathrm{P}<0,05)$ in $\mathrm{B}(40 \pm 17)$ than $\mathrm{A}(29 \pm 10)$, when comparison with $\mathrm{C}$ and $\mathrm{D}$, the births of $\mathrm{A}$ and $\mathrm{B}$ were highly significantly $(\mathrm{P}<0,001)$. According to $(\mathrm{BN})$ the studied region were classified into 3 zone groups: (a) with high lambing rate $(\mathrm{C}, \mathrm{D})$; (b) with medium lambing rate (B); (c) with low lambing (A). In regard to mortality rates, the total rate was $24 \pm 6 \%$. The $(\mathrm{MR})$ in $\mathrm{A}(27 \pm 5 \%)$ was significantly higher $(\mathrm{P}<0,05)$ as compared to other zones $(\mathrm{B})$ $24 \pm 4 \%$, (C) $23 \pm 7 \%$ and (D) $22 \pm 4 \%$. However, no significant differences between B, C and D were revealed. According to the results of (MR) the studied region was classified into two groups: (a) with low MR (C, D), (b) with high MR (A, B). Our result showed that zones influence the (BN) and (MR) in Tébessa region, and southern zones especially D seems the appropriate to practice breeding of Ouled Djellal breed.
\end{abstract}

Keywords: Livestock, Mortality, Birth, System, Lambs, Climate Available online at http://www.vetmedmosul.com

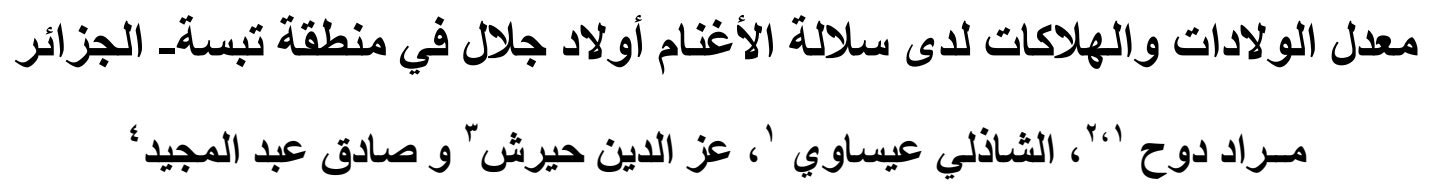

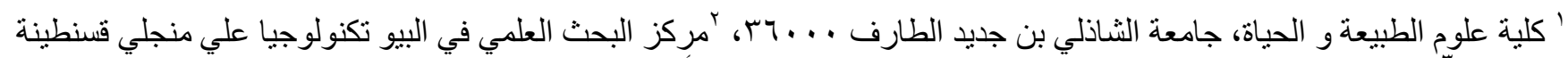

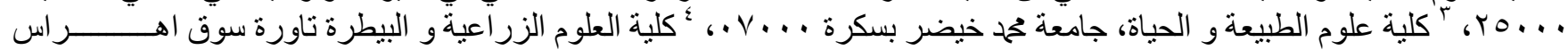
ائر

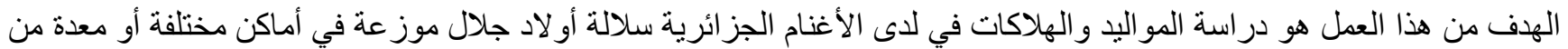

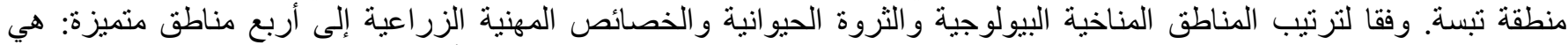

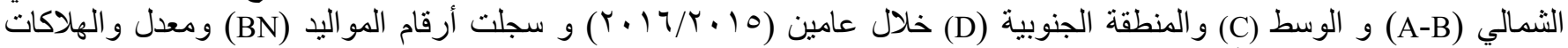

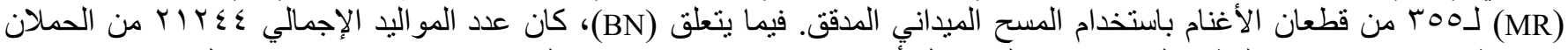

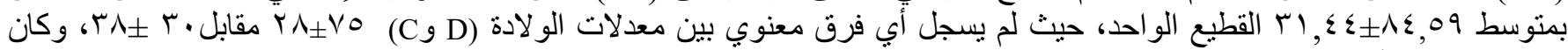

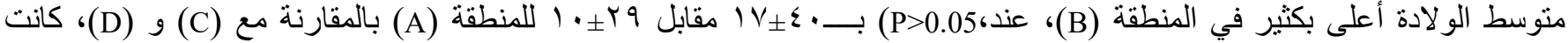




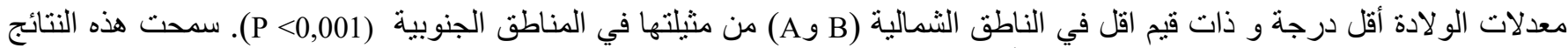

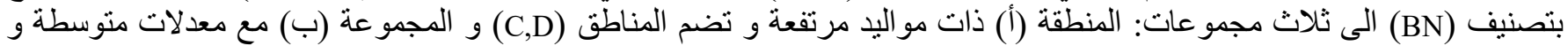

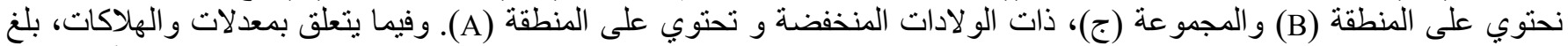

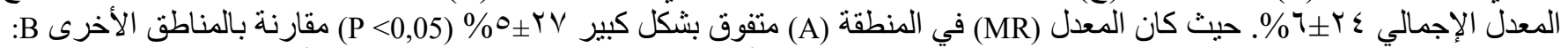
ع r

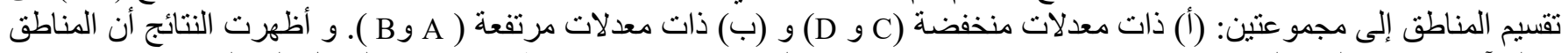

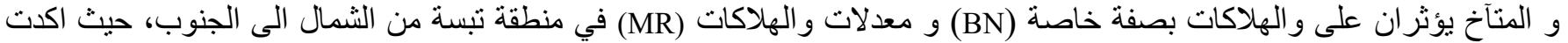
هذه الدراسة ان المناطق الجنوبية وخاصة D تبدو مناسبة لممارسة تربية سلالة أغنام أولاد جلادل

\section{Introduction}

In African, Algeria ranks the second in meat production after Sudan (1). The Algerian sheep have been able to obtain skills characterizing its particular productive performance (2). The livestock sector plays an important role in food security. The sheep population has been progressing despite the aggressions marked by colossal mortality during lambing, the total number of breeding, constituted by the sheep flock (3-7). The sheep population has improved markedly despite the increased mortality influenced by environmental factors which are difficult to be controlled. It is also known that litter size, sexual category of lamb and age of dam may influence lamb mortality (8-10). In general, increasing litter size, male lambs and young dams increase lamb mortality. The OuledDjellal breed is considered among the main breeds (11), granted by (12) it is the preferred given its reputation approved by the best yields and the expansion of its natural cradle, it occupies a prominent place nationally $(58 \%)$ and the Maghreb country's (13-15). However its performance (births and deaths) remains unknown, as it has not benefited from research programs (16).

Sheep farming in the Tebessa region has a population of 900000 flocks of which $58 \%$ are female (17). Conducted almost entirely under an extensive system and an arid climate, makes the profitability of this speculation mediocre. Submitted directly in the face of harsh climatic conditions where the control variable is difficult negatively affects performance (births and deaths). Should mortality registrations be established should control and constantly fight to address these risk factors for obtaining a profitable breeding, the objective of minimizing mortalities to the maximum. This is the objective of our study to highlight the performance of the Ouled-Djellal ewes, to record the births and its annual distributions, to quantify the mortalities and the factors in question, justifying the major handicap blocking the good sustainable development of these farms whose conduct remains to this day carried out in ancestral forms.

\section{Material and method}

\section{Study zone}

Through a retrospective survey based on figures collected from farmers in the Tebessa region (Figure 1); where the study was conducted in 2015-2016 annual period campaign, both to determine how the farmer apprehends births and lamb mortality to determine the level and causes of these losses, and to learn more about the driving practices and techniques used in the past farrowing. 355 sheep farms dislocated in four blocks (A, B, C and D), presenting sub-regions classified under different criteria such as the bioclimatic stage, numbers per farm, concentration of farmers, (Table 1). Tebessa region is located in the extreme East, border Algeria-Tunisian on an area of $13.878 \mathrm{Km}^{2}$, latitude: $35^{\circ} 24^{\prime} 15$ "North, longitude $8^{\circ}$ 07'27" East altitude: $867 \mathrm{~m}$, under a floor bioclimatic semiarid divided into four sub-stages from north to south.

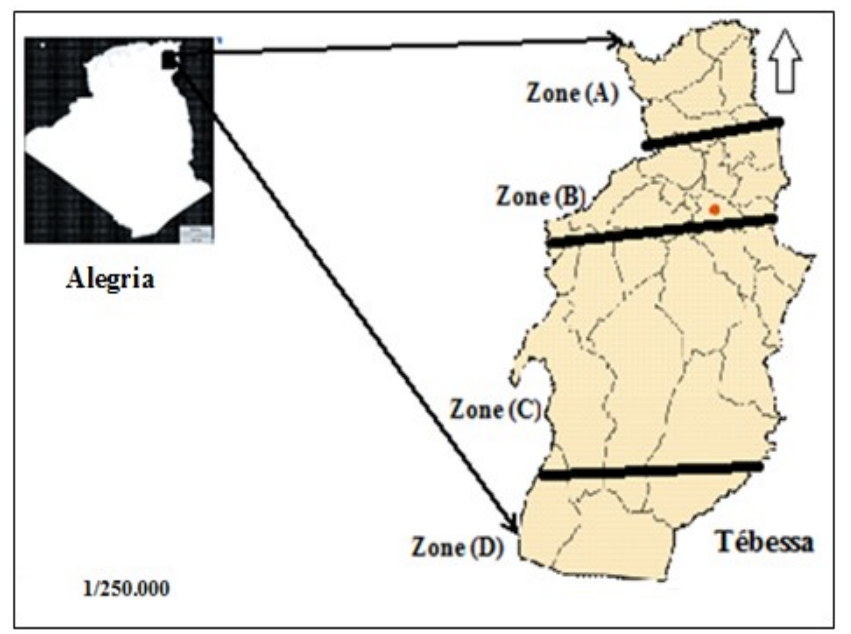

Figure 1: Geographical location of the studied area.

\section{Statistical analysis}

According to the survey conducted for 24 months (2015-2016), out of 355 farms scattered over the studied area (table 2), births and average mortalities recorded on all the farms inspected amounted to 21,244 lambs, with mean 
of $59,84 \pm 31,48$. The data were expressed as means \pm standard deviation. The differences between means of the groups were calculated using a unidirectional analysis of variance, comparison of $\mathrm{k}$ samples. This multiple comparison test was performed to test the significance of differences between all groups using XLSTAT- Statistics Package for Excel (18).

\section{Results and discussion}

\section{Productive performance of the Ouled-Djellal ewes}

The performances of the Ouled-Djellal ewes mark differences influenced by the farming method adopted and environmental factors. The average of the total births registered in the Tebessa region is 21,244 thus representing a mean of $59,84 \pm 31,48$ distributed as follows: 1971 births in zone (A) $(29,86 \pm 10,63)$; 3392 in zone (B) $(40,86 \pm$ 17,23), 12230 in zone (C) $(75,96 \pm 28,06)$ and 3651 in zone (D) $(83,13 \pm 30,82)$ (Table 2).

\section{Recorded births}

The total average births recorded for the 355 farms are in the order of $45,78 \pm 25,13$; marked by an appropriate distribution according to the appropriate mode of conduct. The statistical analysis shows the diversity of the studied variable births compared to the different sites of stay of the flocks. The treatment between zones shows the existence of the dissimilarities (Contrast), between zones (A, B, C and D) (Tables 3, 4), (Figure 1) justified by the marked standardized differences bearing important values.

Table 1: Socio-economic characteristics of the study area (Tebessa)

\begin{tabular}{lccccc}
\hline Designation & Zone A & Zone B & Zone C & Zone D & Total \\
\hline Total Flock (Unit) & 895 & 1123 & 2172 & 585 & 4775 \\
Sample (Flock) & 66 & 83 & 161 & 45 & 355 \\
Breeding females & 2433 & 4136 & 14597 & 4311 & 25477 \\
Females farrowed & 1848 & 3197 & 11226 & 3352 & 19623 \\
\hline
\end{tabular}

Table 2: Production Performance by Zone in Study Area (Tebessa)

\begin{tabular}{|c|c|c|c|c|c|c|}
\hline \multicolumn{2}{|c|}{ Designations } & Zone A & Zone B & Zone $\mathrm{C}$ & Zone D & Total \\
\hline \multicolumn{2}{|c|}{ Females in farrowing } & 1848 & 3197 & 11226 & 3352 & 19623 \\
\hline \multirow{4}{*}{ Births } & Spring & 610 & 1122 & 4375 & 1203 & 7310 \\
\hline & Summer & 185 & 305 & 698 & 921 & 2109 \\
\hline & Autumn & 395 & 656 & 2300 & 159 & 3510 \\
\hline & Winter & 781 & 1309 & 4857 & 1368 & 8315 \\
\hline \multicolumn{2}{|c|}{ Total live and dead births } & 1971 & 3392 & 12230 & 3651 & 21244 \\
\hline \multicolumn{2}{|c|}{ Mean } & $29,86 \pm 10,63$ & $40,86 \pm 17,23$ & $75,96 \pm 28,06$ & $83,13 \pm 30,82$ & $59,84 \pm 31,48$ \\
\hline \multirow{4}{*}{$\begin{array}{l}\text { Mortality } \\
\text { by age } \\
\text { group }\end{array}$} & Stillborn & 166 & 210 & 940 & 194 & 1510 \\
\hline & From 1 to 2 months & 192 & 353 & 1023 & 377 & 1945 \\
\hline & From 2 to 4 months & 105 & 166 & 678 & 178 & 1127 \\
\hline & More than 4 months & 54 & 84 & 196 & 76 & 410 \\
\hline \multicolumn{2}{|c|}{ Mortality recorded } & 517 & 813 & 2837 & 825 & 4992 \\
\hline
\end{tabular}

Table 3: Analysis of the differences between the modalities: Zones / Tukey (HSD), with a 95\% confidence interval

\begin{tabular}{lccccc}
\hline Contrast & Difference & Standardized difference & Critical value & Pr $>$ Difference & Significant \\
\hline D vs A & 51,2697 & 11,1234 & 2,5691 & $<0,0001$ & Yes \\
D vs B & 40,2659 & 9,1230 & 2,5691 & $<0,0001$ & Yes \\
D vs C & 5,1706 & 1,2861 & 2,5691 & 0,5718 & No \\
C vs A & 46,0991 & 13,2289 & 2,5691 & $<0,0001$ & Yes \\
C vs B & 35,0953 & 10,8935 & 2,5691 & $<0,0001$ & Yes \\
B vs A & 11,0038 & 2,7985 & 2,5691 & 0,0264 & Yes \\
\hline
\end{tabular}

Critical value of Tukey d: 3,6332. 
Table 4: Synthesis of Multiple Comparisons by Zones (Tukey (HSD)

\begin{tabular}{llllll}
\hline Modality & $\begin{array}{l}\text { Estimated } \\
\text { average }\end{array}$ & $\begin{array}{l}\text { Standard } \\
\text { error }\end{array}$ & Groups & \\
\hline D & 81,1333 & 3,5541 & a & & \\
C & 75,9627 & 1,8790 & a & & \\
B & 40,8675 & 2,6170 & & b & \\
A & 29,8636 & 2,9347 & & & c \\
\hline
\end{tabular}

A significant difference between births recorded in the northern zones (A and B), marked by a standardized dissimilarity estimated at 2,5691, or $\operatorname{Pr}>$ Diff is 0,0264 .

A highly significant difference with a probability greater than the difference is $(\operatorname{Pr}>0,005<0.0001)$, between births recorded in the northern zones (A and D), marked by a standardized dissimilarity estimated at 11,1234 , between (B and D) marked by a standardized dissimilarity estimated at 9,1230; between ( $\mathrm{A}$ and $\mathrm{C}$ ) marked by a standardized dissimilarity estimated at 13,2289; and finally between (B and C) marked by a standardized dissimilarity estimated at 10,8935 (table 3). This analysis allows us to put these births into three groups, under separate letters group a includes the area $(\mathrm{C}$ and $\mathrm{D})$; group $\mathrm{b}$ includes area $(\mathrm{B})$ and group $\mathrm{c}$ includes area (A), (Table 4).

A non-significant difference between births recorded in the northern areas (C and D), marked by a standardized dissimilarity estimated at 1,2861, or the $\operatorname{Pr}>$ Diff is 0,5718 .

These differences influenced by environmental factors (climate and others), where the animal finds more favorable conditions and a well-being in a favorable open space (CD), hypothesis agreed and justified by the transhumant system $(90,93 \pm 23,71)$ and the semitranshumant $(81,99 \pm 25,71)$ in front of that of the sedentary $(35,18 \pm 12,42)$ (Table 5), or the animal is housed in a limited place (Zriba, stall... etc.), Grouped In condensed numbers a less ventilated ambient area even in some cases no one, standard, undifferentiated food, on the other hand the first two modes of livestock management system, has multiple advantages where the animal is in the free state, wide spacing, varied diet, ambient climate, offers the animal an ideal atmosphere. The spatial variation of lambing observed (figure 3), reflects the poor level of flock management. Influenced by intra and extrinsic factors, the level of management is conditioned by the human and material capacities of the farm and the effectiveness of food control (availability in quantity and quality). According to a large mass of breeders $(82 \%)$, the selected, well-fed ewes produce good offspring justified by the permanent management of the flock, the aim of which reflects the performance traits during good seasons with variable availability and increased pasture granted by $(12,19)$.
Table 5: Differentiation of lambing by appropriate breeding system

\begin{tabular}{llll}
\hline \multirow{2}{*}{ Designation } & \multicolumn{3}{c}{ Appropriate breeding system } \\
\cline { 2 - 4 } & Transhumant & $\begin{array}{c}\text { Semi- } \\
\text { transhumant }\end{array}$ & Sedentary \\
\hline $\begin{array}{l}\text { Average } \\
\text { births }\end{array}$ & $90,93 \pm 23,71$ & $81,99 \pm 25,71$ & $35,18 \pm 12,42$ \\
\hline
\end{tabular}

Births have a tendency to focus during the winter season with rates of $39,14 \%$, favored by the reason of forage availability in contrast to the cold variant followed by the spring season $(34,41 \%)$, granted by the majority of the respondents justified by a food abundance. Followed by the autumn fall season $(16,52 \%)$ (figure 3), where the lamb called "Rebai" flying saying early, is highly desirable, which leads the rancher to take advantage of the high price of lambs finished in winter and easily marketed; while they are $9.93 \%$ in the summer season (Figure 2). This distribution shows a decline in the registration of lambing in dry periods, especially in summer when the percentage hardly exceeds $(06 \%)$, caused by high temperatures which affect reproduction. In ewes the increase in the radiates heat load (when the animal is exposed to solar radiation greatly reduces the behavior of heat in females). Temperature also acts indirectly during mating periods because rams are subjected to high temperatures during dry seasons. $\left(40-50^{\circ}\right.$ C) this increases the risks of non-fertilizing projections. From where, it is possible that the reduction of the rate of ovulation is due to a stress effect, particularly of climatic origin. Research approved by (20), similar to those found on the European continent (Norwegian breeds), justify that the average mortality of summer lambs in the farms does not exceed $10 \%$.

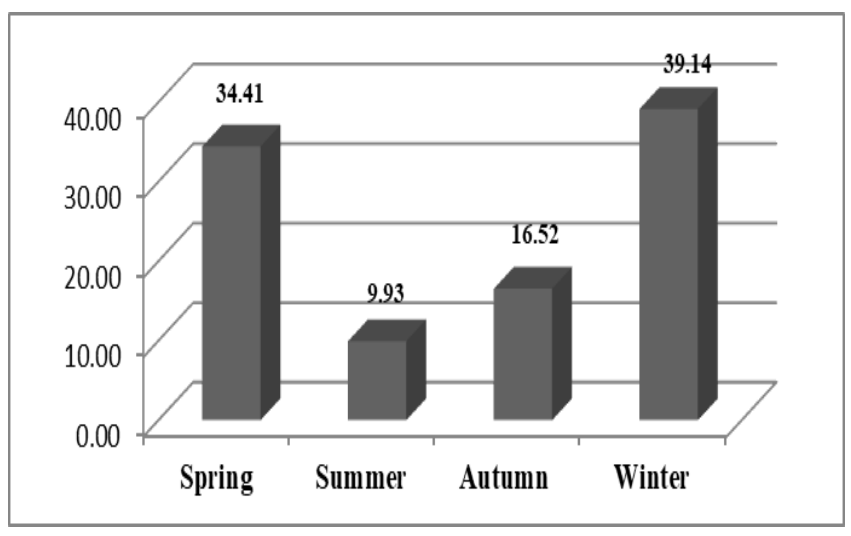

Figure 2: Seasonal distribution rate of lambing in studied area. 


\section{Recorded mortalities}

Considered as the real handicap in farms under the extensive system where the rates mark colossal figures given the magnitude of its seriousness on the continuity and sustainability of these practices in rather difficult areas in terms of vital existence. The distribution of the average total frequencies of individual lamb mortalities reported by area reveals zone dissimilarities. The total average is $24,11 \pm 6,65$; influenced by the driving factor, and the zone of stays is $27,01 \pm 5,70$ in zone (A); $24,20 \pm 4,84$ in zone (B); from 23,25 $\pm 7,86$ in zone (C) and at the end 22,78 \pm 4,70 in zone (D) (figure 4).

The statistical analysis revealed differences in mortality between zones (A, B, C and D), diffuse diversity of the studied variable (mortality rate). These show the existence of dissimilarities (Contrast), between areas, justified by the standardized differences between areas (AD) (AC) (AB) (BD) (BC) and (CD) with significant values), are as follows (Table 8 and 9 ).

A significant difference between the mortalities recorded between zones (A-B), marked by standardized dissimilarities estimated at 2,6141 or the $\operatorname{Pr}>$ Diff (table 8 and 9).

A highly significant difference between the mortality recorded between zones (A-D) and (A-C), marked by standardized dissimilarities estimated at 3,3594 and 3,9470 or the $\operatorname{Pr}>$ Diff. The average viability of lambs in north African was $75,88 \%$. This rate was similar in males and females, as well, as reported in other studies, those recorded in lambs of certain breeds such as Sardi, Beni Guil and D'man who varied on average from 75 at $93 \%$. $(5,6,8,21)$. The analysis (Figure 3), (Table 6), allows us to group the variable prolificity into two groups, under distinct letters the group a include the zone (A), the group b encompasses the zones (B, C and D) (Table 7).

A non-significant difference in the recorded mortality between zones (B-D) (B-C) (C-D), marked by dissimilarities estimated at 1,$1793 ; 1,0787$ and 0,4303 , or the Pr> Diff.

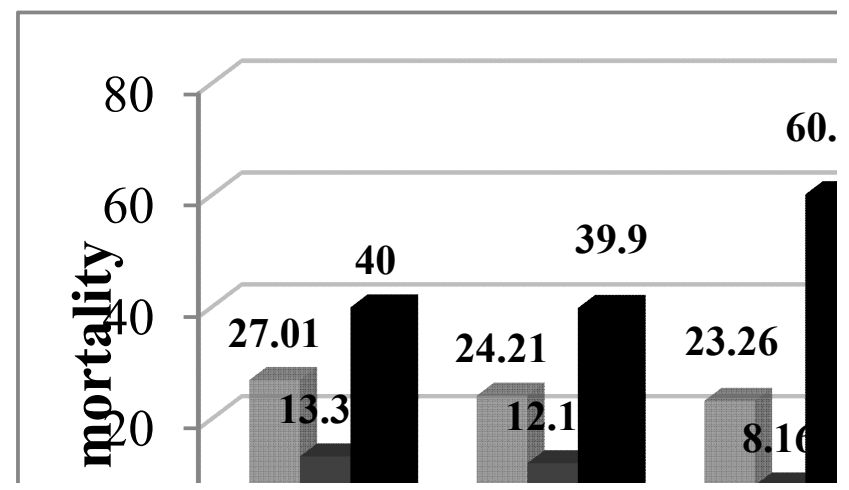

Figure 3: Graphical representation of mortality in studied areas.

Table 6: Analysis of the differences between the Zones / Tukey (HSD) modalities, with a 95\% confidence interval

\begin{tabular}{cccccc}
\hline Contrast & Difference & Standardized difference & Critical value & Pr $>$ Diff & Significant \\
\hline A vs D & 4,2338 & 3,3594 & 2,5691 & 0,0043 & Yes \\
A vs C & 3,7607 & 3,9470 & 2,5691 & 0,0005 & Yes \\
A vs B & 2,8105 & 2,6141 & 2,5691 & 0,0443 & Yes \\
B vs D & 1,4232 & 1,1793 & 2,5691 & 0,6399 & No \\
B vs C & 0,9502 & 1,0787 & 2,5691 & 0,7026 & No \\
C vs D & 0,4730 & 0,4303 & 2,5691 & 0,9733 & No \\
\hline
\end{tabular}

Table 7: Synthesis of Multiple Comparisons by Zones (Tukey (HSD)

\begin{tabular}{|c|c|c|c|}
\hline Modality & $\begin{array}{c}\text { average } \\
\text { Estimated }\end{array}$ & $\begin{array}{c}\text { Standard } \\
\text { error }\end{array}$ & Groups \\
\hline A & 27,0167 & 0,8024 & $\mathrm{a}$ \\
\hline B & 24,2061 & 0,7156 & b \\
\hline $\mathrm{C}$ & 23,2559 & 0,5138 & $\mathrm{~b}$ \\
\hline D & 22,7829 & 0,9718 & $\mathrm{~b}$ \\
\hline
\end{tabular}

The low marked viability rate $(72,98 \%)$ in sedentary farms in zones (A and B) compared to transhumant zone (C and D) can be explained by the food availability handicap, which reflects on the milk production of ewes negatively affects weight and survival rate. In contrast, the weight of the lambs of the undernourished ewes is significantly reduced. Reported by (22). A body condition which is too weak or too large is also associated with an increased risk of pregnancy toxemia and lower milk production. These variations explain the interference between food availability and the exhortation of body reserves according to the physiological stage; hypothesis is given by several studies related to this subject $(3,12,23,25)$.

\section{Distribution of mortalities by age class of lambs}

According to (26), Mortality due to general weakness and debility could be accredited to the lower nutritional regime. The early neonatal mortality rate after $48 \mathrm{~h}$ of 
lambing was $2,01 \%$ and represented $62,1 \%$ of the neonatal mortalities with starvation-mis-mothering-exposure as one of the main factor. According to (27), The majority of lamb deaths from birth to weaning occur in the first days after birth and range from 5 to $30 \%$ for individual sheep flocks observation of data (Figure 4), reveals a rather spectacular distribution of monthly mortalities, justified by the age classes of the births or the mortalities are observed, this one presumes very high rates $38,96 \%$, especially during the seasons cold (fight in the Autumn season), focused on the age range from one to two months followed by births known as stillbirth representing a high rate of up to $30,25 \%$, and in third and fourth position is those distributed between 2 to 4 months and more (22,58\% and $8,21 \%$ respectively).

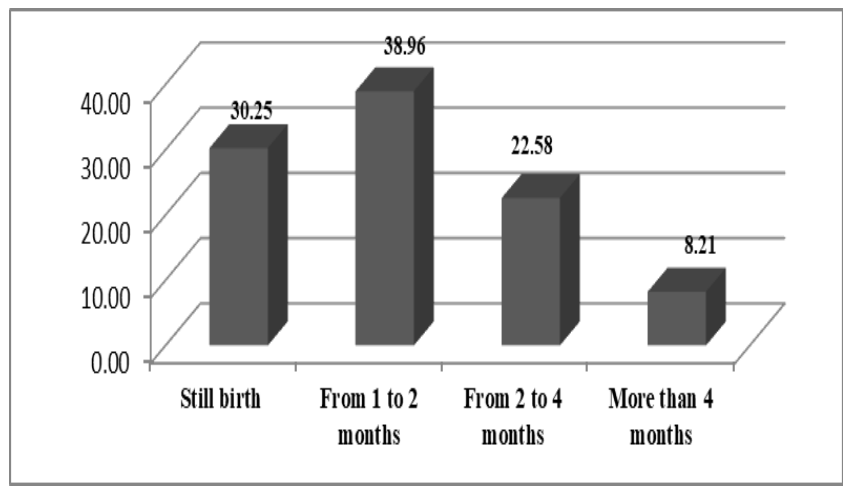

Figure 4: Annual distribution of mortalities of lambs by age group.

\section{Multiple causes of recorded mortalities}

The multiplicity of causes of mortality sometimes makes it difficult to identify them, when the diagnosis of consubstantial diagnosis via the appropriate methods of breeding, and the areas of flocks (steppe) stays based solely on the observation of the breeder. (28), reported that the proportion of mortalities and causes are large and indeterminate by the breeder (>20\%), and maximum (50\%) among stillbirths. The main cause of mortality mentioned by the interviewed breeders $(70 \%)$ was the lack of food (less milk or unavailable) especially in cases of triple births. These results are consistent with those of $(5,29,21)$ who reported that 50 to $80 \%$ of the losses occur during the first week of lambing. The high average of the factors raised was the weight influenced by the size of the litter (single, double and triple) and the feed satisfaction rate (Breastfeeding), where $60 \%$ of breeders proclaim these factors for three systems followed the season (20 and 30\%) and finally the shelter which presents only a rate of (10 to $20 \%$ ). The small mortality difference between single and double litters and the substantial increase of size two to three justified the hypothesis of the tendency of these losses in lambs (20). According to studies already developed intra- partum or lambing mortality accounts for between $12 \%$ and $45 \%$ (23), where several causes are involved in games, notably the weight of the litter. Nearly $60 \%$ of respondents consider mortality as a concern and an economic handicap. Despite the large differences in mortality between farms more than $80 \%$ of the farmers surveyed said a low input $258 / 355$, or $(72,67 \%)$ of farms in which the recordings of mortalities seem to reach exhaustive reports, the average mortality rate is $24,11 \%$. Mortality in triple-hatched ewes is higher than that in single births, mainly because of a gross deficit in feeding for lambs tripled in front of lamb alone during the same periods of lambing. Assumed hypothesis or mortality in triplets is significantly greater (multiplied by $2-$ 3 ), important cause of mass due to lower birth weight and increased risk of dystocia $(8,17,30$ and 31$)$. According to (32), triplet lambs would be active later in life after birth, regardless of weight, vascular insufficiency, limiting maternal-feotal exchanges, is observed when the uterine horn carries more than two lambs and could participate in this phenomenon $(33,30,34)$.

\section{Conclusion}

The study highlights the importance of climatic factors and the interaction of very hostile ecological factors in the region on the spatio-temporal distribution of lambing in Ouled-Djellal sheep which has very variable performances. Indeed under grazing areas pastoral resources particularly in the southern areas (C and D), where the farrowing is higher indicate an effectiveness in the fight approved by an amplification of reproduction observed marked by interesting prolificacies (from 108 to 109\%). On the other hand, the average mortality recorded has a high mean of $24,11 \pm 6,65$ or it presents a very worrying aspect and a burden for this speculation. The analysis between the modalities with a 95\% confidence interval, asserts the existence of the significant differences between zones studied separately (A, B, C and D).

This variation is at the origin of the strongly nutritional and environmental factors or the control of the flocks passes by the implementation of practices of hygiene and prophylaxis. The control of the mortality of lambs is a major stake of the economic profitability of sheep farms and the sector. The concomitant presence of various causes and many risk factors makes the diagnosis and control of this scourge of mortality of lamb's complex and diversify.

\section{References}

1. Skapetas B, Kalaitzidou M. Current status and perspectives of sheep sector in the world. Liv Res Rural Devel LLRD. 2017;29(2):\#21.

2. Tlidjane M, Meziane $\mathrm{T}$, Touabti A. Influence of the physiological stage on various blood biochemical parameters in the Ouled-Djellal ewe in the arid zones of south-eastern Algeria. Revue. Méd Vét. 2011;162 (1):3-7. 
3. Benyoucef MT, Madani T, Abbas K. Systems of breeding and objectives of selection to ovine races in Algerian semi-arid situation. In: ABIÑA, D. (Ed.) Analysis and definition of the objectives in genetic improvement programs in sheep and goats: An economic approach to increase their profitability. Zaragoza, CIHEAM. Option Mediterranean's. 2000; Serie A:101-109.

4. Benyoucef MT. The Algerian sheep breeds: Situation and perspectives. In Workshop FAO/CIHEAM on Strategy for development of Fat-tail Sheep in near East, Adna (Turkey), 5-9 Oct1992. Publication 1994;68:100-109

5. Boukhlifa A. Monthly, seasonal and annual variation of the various reproduction and mortality parameters of ovine farming: cooperatives established in the steppe [Engineer thesis], El Harrach institute (Algeria); 1979; pp:80.

6. Chellig R. The Algerian ovine races, 1992. 80 p, Office of University Publications (OPU), Algiers.

7. Mekhloufi MB, Mahari L, Mekhloufi F. System's dynamics of sheep farms and driving herds of faces to the vagaries of weather: Cases from the Region of El Bayadh. Agricultural Sciences.2014;5:583-587 Published Online June 2014 in Sci. Res. http: // www.scirp.org / journal /ashttp://dx.doi.org/10.4236/as.2014.57061

8. Christley RM, Morgan KL, Parkin TD, French NP. Factors related to the risk of neonatal mortality, birth-weight and serum immunoglobulin concentration in lambs in the UK. Prev Vet Med. 2003;57(4):209-26.

9. Gama LT, Dickerson GE, Young LD, Leymaster KA. Effects of breed, heterosis, age of dam, litter size, and birth weight on lamb mortality. J Ani Sci. 1991;69(7):2727-2743.

10. Sharif L, Obeidat J, Al-ani F. Risk factors for lamb and kid mortality in sheep and goat farms in Jordan. Bulg J Vet Med. 2005;8:99-108

11. Dehimi M. Characterization of small ruminant breeds in West Asia and North Africa. Vol 2: North Africa. International Center for Agricultural Research in the Dry Areas. Chapter 3, (ICARDA), Aleppo, Syria. 2005;pp:55-99.

12. Lamrani F, Benyounes A. Growth of Ouled Djellal lambs raised on cereal stubble in the region of Guelma, Algeria. LRRD. 2015;27(3):\#43.

13. Bencherit $\mathrm{S}$. The pastoral breeding and the cultivation of cereals in the Algerian steppe Evolution and possibilities of development, [Doctoral thesis]. Institute of Life Sciences and Industries and Environment. (AgroParisTech) 2011;pp:238.

14. Benyoucef MT, Boutebila S, Kaidi R, Khellaf D, Benaissa T, Benzidour A, Zahaf A. Organizational and technical aspects of a genetic curriculum of the ovine race Hamra in the western region (Algeria). Cahiers Options Méditerranéennes. 1995;11:215-224.

15. Kanoun M, Medjras N, Kanoun A. Analysis of sheep farming systems in an environment with a pastoral component: case of the El-Guedid region (Djelfa-Algeria). INRA Algerian International Symposium "Sustainable Development of Animal Production: Issues, Evaluation and Prospects", Algiers. 2008;pp:20-21.

16. Douh M. Characterization of zootechnical parameters of sheep farms in steppe zones: region of Tebessa, [master's thesis]. Chadli Ben Djedid El Taref University, (Algeria). 2011;pp:209.

17. Ministry of Agriculture and Rural Development (MARD). National Report on Animal Genetic Resources, AnGR Commission, Algiers. 2014;pp:46.
18. Addinsoft, XLSTAT- Statistics Package for Excel, Paris (2014). (http://www.xlstat.com/)

19. Benyounes A, Rezaiguia M Lamrani F. Effect of the season of lambing on the mortality of lambs in ovine races Ouled-Djellal; and Taâdmit raised in the northeast of Algeria, Rev. Agri. (Sétif 1). 2013;105;5-9.

20. Steinheim G, Eikje LS, Klemetsdal G, Dnøy TA. Effect of birth weight, gender and litter characteristics on summer mortality in lambs of Norwegian breeds Acta Agriculturae Scand Section A, 2008;58:4550 .

21. Ricordeau G, Tchamitchian L, Lefevre C, Brunel JC. Improvement of the productivity of ewes Berrichonnes of Cher (BC) by crossing. IV. Duration of gestation and viability of lambs Berrichon, Romanov and crusaders F1, F2 and F3. Ann Génét sél Anim. 1977;9:219-239.

22. Wallace JM, Milne JS, Aitken RP. The effect of over nourishing singleton-bearing adult ewes on nutrient partitioning to the gravid uterus. Br J Nutr. 2005;94:533-539.

23. Boujenane I, Bradford GE, Berger YM, Chikhi A. Genetic and environmental effects on growth to one year and viability of lambs from crossbreeding study of D'man and Sardi breeds. J Anim Sci. 1991;69:3989-3998

24. Boujenane I, Chami A. Effect of inbreeding on reproduction, weights and survival of Sardi and Beni Guil sheep. J Anim Breed Genet. 1997;114:23-31.

25. Saadi MA, Megti Korteby H, Benia A, Bellala R, Kaidi R. effect of season and age rams breed "ouled Djellal" on quality of their seed and Reproduction In vivo. Int J Adv Res Biol Sci. 2016;3(5):42-47.

26. Sharif L, Obeidat J, Al-Ani F. Risk factors for lamb and kid mortality in sheep and goat farms in Jordan. Bulgarian J Vet Med. 2005;8:99108.

27. Kerslake JI, Everett-Hincks JM, Campbell AW. Lamb survival: a new examination of an old problem. In: Proceedings of the New Zealand Society of Animal Production; 2005;65:13-18.

28. Gautier JM, Corbiere F. Lamb mortality: state of knowledge. 18. Renc. Rech. Ruminants, (3R) Paris France. 2011;pp:262-265.

29. Prud'hon M, Denoy I, Desvignes A. Parameters of reproduction of females having answered the male effect. Study of the results of six years of breeding of ewes Merino of Arles of the domain of Blackbird. III. The mortality of lambs. Ann Zootech. 1968;17:159-168.

30. Dwyer CM. Behavioural development in the neonatal lamb: effect of maternal and birth-related factors, Theriogenol. 2003;59:699-1086.

31. Everett-Hincks JM, Dodds KG. Management of maternal-offspring behavior to improve lamb survival in easy care sheep systems. J Anim Sci. 2008;86:259-70.

32. Mandal A, Prasad H, Kumar A, Roy R, Sharma N. Factors associated with lamb mortalities in Muzaffarnagari sheep. Small Rumin Res. 2007;71:273-279.

33. Dwyer CM, Morgan CA. Maintenance of body temperature in the neonatal lamb: Effects of breed, birth weight and litter size. J Anim Sci. 2006;84:1093-1101.

34. Rhind S, Robinson M, Mcdonald J. Relationships among uterine and placental factors in prolific ewes and their relevance to variation in foetal weight. Anim Prod. 1980;30:115-124. 